\title{
The role of brand personality, self-congruity, and sensory experience in elucidating sky lounge users' behavior
}

\begin{abstract}
This study attempted to develop an integrated model linking brand personality, self-image congruity, hedonic and utilitarian values, and behavioral intentions in the sky lounge context. Our results indicated that brand personality was significantly related to self-image congruity, which in turn influenced hedonic and utilitarian values. While hedonic value significantly affected intentions to revisit and recommend, utilitarian value significantly influenced intention to recommend. Moreover, self-image congruity and values played a significant mediating role. Furthermore, the links from hedonic value to intentions to revisit and recommend, and from utilitarian value to intention to revisit were significantly moderated by sensory experience.
\end{abstract}

Keyword : Brand personality; Self-congruity; Perceived value; Behavioral intentions; Sensory experience; Sky lounge 